\title{
Conjunctival impression cytology with transfer (CICT) to detect pre-clinical vitamin A deficiency among slum children in India
}

\author{
BY SWAPAN CHOWDHURY ${ }^{1}$, RAJESH KUMAR ${ }^{2}$, N. K. GANGULY ${ }^{1 *}$, \\ LATA KUMAR ${ }^{3}$, C. K. NAIN ${ }^{1}$ AND B. N. S. WALIA ${ }^{3}$ \\ Departments of ${ }^{1}$ Experimental Medicine, ${ }^{2}$ Community Medicine, and ${ }^{3}$ Paediatrics, \\ Postgraduate Institute of Medical Education and Research, Chandigarh-160012, India
}

(Received 14 January 1994 - Revised 17 July 1995-Accepted 15 September 1995)

\begin{abstract}
In order to establish a method usable in the field for diagnosis of pre-clinical vitamin A deficiency, conjunctival impression cytology with transfer (CICT) was used in 200 normal slum children aged 6-120 months in Chandigarh, India. Conjunctival impressions taken on cellulose acetate paper were transferred to glass slides which were fixed in ethanol and stained with alcian blue and carbol fuchsin. Sixty samples of cellulose acetate paper were preserved after transfer of impression and were stained later. Transfer was complete in forty-eight samples and in the other twelve it was incomplete. Conjunctival impressions on paper and slide of these twelve cases were comparable. At a plasma retinol concentration of < $0.70 \mu \mathrm{mol} / 1$ measured by HPLC the sensitivity, specificity and positive predictive values of CICT were $\mathbf{9 0 . 5 9} \%, 100 \%$ and $100 \%$ respectively. Compared with conventional conjunctival impression cytology, CICT is less time consuming, cheaper and comparable in validity. It is thus more suitable than the conventional method for mass screening.
\end{abstract}

Conjunctival impression cytology with transfer: Vitamin A: Retinol

The prevalence of pre-clinical vitamin A deficiency is considered to be greater than that of xerophthalmia (Sommer, 1989). Detection of pre-clinical vitamin A deficiency is important for identification of risk group, early intervention, and evaluation of the on-going supplementation programme in the community.

Conjunctival impression cytology (CIC) has been proposed as a simple and objective method for detecting vitamin A deficiency (Wittpenn et al. 1986; Natadisastra et al. 1988; Gadomski et al. 1989; Reddy et al. 1989). However, large variations in sensitivity and specificity of CIC were reported from Indonesia (Natadisastra et al. 1988) and Guatemala (Gadomski et al. 1989). Moreover, the applicability of the usual CIC method was limited in mass screening programmes due to higher costs, unacceptable time required for the staining procedure, and necessity of an adequate laboratory and trained personnel.

Luzeau et al. (1988) and Carlier et al. (1991 a) suggested a simple technique of transfer of the conjunctival epithelium sample from the adhesive paper strip to a glass slide which saved time and reduced the cost of staining of the CIC procedure. Carlier et al. (1991 b) also used this modified technique, referred to as conjunctival impression cytology with transfer (CICT), in Senegalese pre-school children and reported a wide range of sensitivity $(14.3-53.9 \%)$ and specificity (57.3-96.4\%) depending on the classification of CICT.

Thus, the present study was designed to examine the suitability of CICT for estimating the prevalence of pre-clinical vitamin A deficiency under field conditions in India where vitamin A deficiency is a serious public health problem (Indian Council of Medical

* For reprints. 
Research, 1974). The aims of the study were: (1) to test the feasibility of using CICT in the field; (2) to compare the sensitivity, specificity and positive predictive value of CICT with plasma retinol concentrations, and (3) to describe the vitamin A status of a poor slum community.

\section{SUBJECTS AND METHODS}

Two hundred children aged 6-120 months who had not received a massive oral dose of vitamin A within the previous 6 months and who were not suffering from xerophthalmia, gross protein-energy malnutrition (marasmus or kwashiorkor), or any other chronic disease were selected at random from a sampling frame of 1500 children from a slum community in Chandigarh, India. Informed consent from the parents and approval of the ethical committee of the Institute were obtained.

For collection of conjunctival impressions, a strip of cellulose acetate paper (Celagram II, Shandon Southern Instruments Ltd, Camberley, Surrey) of approximately $3 \mathrm{~mm} \times 15 \mathrm{~mm}$ in size was applied to the bulbar conjunctiva (one strip separately to each eye) for about 2-3 s. This was taken off with gentle peeling before the child could blink or cry. The impression collected on the paper strip was transferred immediately to a clean glass slide applying light finger pressure. The slide with the impression was placed in ethanol $(950 \mathrm{ml} / 1)$ for $15 \mathrm{~min}$, dried and kept in a staining solution containing a mixture $(2: 1, \mathrm{v} / \mathrm{v})$ of alcian blue $(2 \mathrm{~g} / 1$ in $50 \mathrm{ml} / 1$ acetic acid) and carbol fuchsin $(10 \mathrm{~g} / 1$ basic fuchsin in ethanol $(950 \mathrm{ml} / \mathrm{l})$-phenol $(50 \mathrm{~g} / \mathrm{l}) ; 1: 1, \mathrm{v} / \mathrm{v})$ for $15 \mathrm{~min}$. After washing thoroughly in tap water, the slides were examined under a light microscope. Nuclei and cytoplasm of non-goblet epithelial cells and nuclei of goblet cells stained pink with acid fuchsin. Goblet cells and mucin spots were stained black with alcian blue. Sheets of small epithelial cells having a normal nucleus: cytoplasm ratio together with goblet cells and/or mucin spots were regarded as being indicative of normal conjunctival epithelium, whereas enlarged epithelial cells of different sizes and shapes with small or pyknotic nuclei and absence of goblet cells and mucin spots were regarded as being indicative of abnormal conjunctival epithelium and of vitamin A deficiency. No attempt was made to classify conjunctival changes in different stages. A child with abnormal CICT in either eye was regarded as having an abnormal CICT test. In case of failure of the CICT in one eye, the result of the other eye was used to categorize the child.

In the CICT procedure we also tried a single-stage staining and fixation technique (Carlier et al. 1991 a) for a few samples, but the double-stage fixation and staining technique (Luzeau et al. 1988) was found to give better staining of the smear. Experience in the sampling procedure and immediate transfer onto a cool glass slide are critical. Care should be taken to apply and take off the paper strip before the child cries or blinks. Co-operation of the child is important and instruments such as scissors or forceps which may frighten the child should be kept out of sight.

The paper strip was preserved after transfer of the impression, in a ninety-six-well tray containing fixative solution of glacial aceticacid-formaldehyde $(370 \mathrm{ml} / 1)$ ethanol $(700 \mathrm{ml} / 1)$ $(1: 1: 20$, by vol.). Sixty samples on paper strips were stained several days later using periodic acid-Schiff and haematoxylin (Reddy et al. 1989) to cross check the efficacy of transfer and efficiency of sample collection. At the time when the CIC specimen was collected, a venous blood sample $(2 \mathrm{ml})$ was obtained through a 21 gauge needle with a syringe into a glass tube containing EDTA and wrapped with carbon paper. Samples were collected between 09.00 and 17.00 hours without fasting. Plasma was separated on the same day and stored at $-20^{\circ}$. Within 4 months of blood collection, retinol was extracted and analysed by HPLC (Thurnham et al. 1988). In brief, $200 \mu \mathrm{l}$ plasma was mixed with $200 \mu \mathrm{l}$ $10 \mathrm{~mm}$-sodium dodecyl sulphate. The sample was deproteinized with $400 \mu 1$ ethanol and 
Table 1. Vitamin A status as assessed by conjunctival impression cytology with transfer and plasma retinol concentration in a sample of 190 slum children in India

\begin{tabular}{|c|c|c|c|}
\hline \multirow{2}{*}{$\begin{array}{l}\text { Plasma retinol } \\
\text { concentration } \\
(\mu \mathrm{mol} / \mathrm{l})\end{array}$} & \multicolumn{3}{|c|}{$\begin{array}{l}\text { Conjunctival impression } \\
\text { cytology with transfer }\end{array}$} \\
\hline & Normal & Abnormal & Total \\
\hline$<0.01$ & - & 98 & 98 \\
\hline $0.01-<0.18$ & - & 11 & 11 \\
\hline $0.18-<0.35$ & - & 20 & 20 \\
\hline $0.35-<0.53$ & 2 & 23 & 25 \\
\hline $0.53-<0.70$ & 14 & 2 & 16 \\
\hline $0.70-<0.88$ & 6 & - & 6 \\
\hline $0.88-<1.05$ & 5 & - & 5 \\
\hline $1.05-<1.23$ & 1 & - & 1 \\
\hline $1 \cdot 23-<1.75$ & 2 & - & 2 \\
\hline $1 \cdot 75-<2 \cdot 80$ & 3 & - & 3 \\
\hline $2 \cdot 80-<3 \cdot 17$ & 3 & - & 3 \\
\hline Total & 36 & 154 & 190 \\
\hline
\end{tabular}

finally extracted with $1000 \mu \mathrm{l} n$-heptane. After centrifugation at $2500 \mathrm{~g}$ for $10 \mathrm{~min}$ the supernatant fraction was transferred to another tube and dried under a gentle stream of $\mathrm{N}_{2}$ at $60^{\circ}$. The sample was then reconstituted in mobile phase (acetonitrile-methanolchloroform: 47:47:6, by vol.) and injected into a $\mu$ Bondapak C18 column (3.9 mm $\times 300 \mathrm{~mm}$; Waters, Division of Milipore Corporation, Vienna, Austria), eluted at a flow rate of $1.8 \mathrm{ml} / \mathrm{min}$, and its retinol was monitored at $325 \mathrm{~nm}$. The results of CICT were compared with plasma retinol concentrations.

Sensitivity, specificity and positive predictive value of CICT were determined against plasma retinol concentrations of $<0.70 \mu \mathrm{mol} / 1$. For proportions, $95 \%$ confidence intervals (CI) were estimated using normal approximation to the binomial distribution.

\section{RESULTS}

Conjunctival impressions and blood samples could not be obtained from two children due to non co-operation. Of the remaining 198 children, CIC specimens were successfully obtained from at least one eye in 190, and from both eyes in 176 children. No severe complication other than mild watering from the eye for a few minutes was noted following the test. In one child a minor subconjunctival punctate haemorrhage following sampling was observed. Sample collection was more difficult in children between the ages of 2 and 3 years. All eight children in whom no impression could be collected and the fourteen children in whom impression could be obtained from only one eye belonged to this age group.

Out of sixty samples of paper strip tested for the evaluation of the efficacy of transfer in CICT, in forty-eight $(80 \%)$ cases transfer was complete and in twelve it was partial but sufficient to allow a correct evaluation. Conjunctival impressions of these twelve samples were similar on paper and slide.

The vitamin A status of study children as assessed by impression cytology and plasma retinol concentration is shown in Table 1 . The prevalence of severe vitamin A deficiency (plasma retinol values $<0.35 \mu \mathrm{mol} / \mathrm{l}$ ) was $68 \%$ (95\% CI 61.5-74.5\%). A plasma retinol concentration of $<0.70 \mu \mathrm{mol} / 1$ was considered as the criterion for vitamin A deficiency. At 
Table 2. Sensitivity, specificity and positive predictive values of conjunctival impression cytology with transfer compared with plasma retinol concentration in slum children in India

\begin{tabular}{|c|c|c|c|}
\hline \multirow[b]{2}{*}{ Conjunctival impression cytology } & \multicolumn{2}{|c|}{ Plasma retinol concentration } & \multirow[b]{2}{*}{ Total } \\
\hline & $<0.70 \mu \mathrm{mol} / 1$ & $\geqslant 0.70 \mu \mathrm{mol} / 1$ & \\
\hline $\begin{array}{l}\text { Abnormal } \\
\text { Normal }\end{array}$ & $\begin{array}{r}154 \\
16\end{array}$ & $\begin{array}{r}0 \\
20\end{array}$ & $\begin{array}{r}154 \\
36\end{array}$ \\
\hline $\begin{array}{ll}\text { Sensitivity } & =154 / 17 \\
\text { Specificity } & =20 / 20> \\
\text { Positive predictive value } & =154 / 15\end{array}$ & \multicolumn{2}{|c|}{$\begin{array}{l}=154 / 170 \times 100=90.6 \%(95 \% \text { CI } 86.2-95.0 \%) \\
=20 / 20 \times 100=100 \% \\
=154 / 154 \times 100=100 \%\end{array}$} & \\
\hline
\end{tabular}

this threshold the sensitivity of CICT was $90 \cdot 6 \%(95 \% \mathrm{CI} 86 \cdot 2-95 \cdot 0 \%)$. Specificity and positive predictive values were $100 \%$ (Table 2 ).

Children with abnormal CICT had a mean plasma retinol concentration value of $0.13 \mu \mathrm{mol} / 1$ compared with $1.09 \mu \mathrm{mol} / 1$ for those with normal CICT. There was no significant difference in plasma retinol concentration between the sex groups. Mean plasma retinol concentrations were 0.86 and $0.78 \mu \mathrm{mol} / 1$ in males and females respectively. However, mean plasma retinol concentration of children under 5 years old was $0.70 \mu \mathrm{mol} / 1$ compared with $0.93 \mu \mathrm{mol} / 1$ among children aged 5-10 years. Prevalence of abnormal CICT in under-5-year-olds was $88 \%$ compared with $80 \%$ among older children (5-10 years). However, there was no difference between the sexes in the proportion of abnormal CICT.

\section{DISCUSSION}

The technique of CICT used in the present study was found to be quite acceptable to the children and their families. Samples were collected at the house where the child lived. Preservation and staining of samples did not require a strict time frame, therefore this procedure was carried out simultaneously while the sample collection was going on in the field. Sensitivity and specificity were found to be good (Table 2).

For determining the sensitivity and specificity of CICT, comparisons were done with plasma retinol concentration values in the absence of any other field feasible gold standard. Other standards such as relative dose response and liver concentration of vitamin $A$ are not feasible in the field as these procedures require repeated blood or tissue sampling. Although plasma retinol concentration is not considered to be a reliable index of pre-clinical vitamin A-deficiency status (Olson, 1984), the World Health Organization (1982) has described plasma retinol concentration as a useful indicator of excessive, deficient and possibly marginal vitamin A status of a community. This is also supported by Pilch (1987). While testing the validity of CICT in the absence of known 'norms' or 'standards' for plasma retinol concentrations in Indian children, we used the commonly accepted criterion of $<0.70 \mu \mathrm{mol} / 1$ for vitamin A deficiency as used by Natadisastra et al. (1988) and Gadomski et al. (1989). Carlier et al. (1991b) used a plasma retinol concentration cut-off value $<0.35 \mu \mathrm{mol} / 1$; against this threshold value the sensitivity and specificity of CICT in the present study were found to be $100 \%$ and $59 \%$ (95\% CI 46.7-71.3\%) respectively.

Sensitivity and specificity of CICT in the present study differed from those of Natadisastra et al. (1988) from Indonesia, Gadomski et al. (1989) from Guatemala and Carlier et al. (1991 b) from Senegal (Table 3). In the latter two studies CIC was less sensitive but more specific. The reason for the lower sensitivity of CIC/CICT in these two studies 
Table 3. Sensitivity and specificity of conjunctival impression cytology (CIC) and conjunctival impression cytology with transfer (CICT) in various studies

\begin{tabular}{lllccc}
\hline Reference & Country & Method & $\begin{array}{c}\text { Plasma retinol } \\
\text { concentration } \\
\text { cut-off level }\end{array}$ & $\begin{array}{c}\text { Sensitivity } \\
(\%)\end{array}$ & $\begin{array}{c}\text { Specificity } \\
(\%)\end{array}$ \\
\hline Natadisastra et al. $(1988)$ & Indonesia & CIC & $<0 \cdot 70 \mu \mathrm{mol} / 1$ & $61 \cdot 8$ & 88.5 \\
Gadomski et al. $(1989)$ & Guatemala & CIC & $<0.70 \mu \mathrm{mol} / 1$ & 26 & 81 \\
Carlier et al. $(1991 \mathrm{~b})$ & Senegal & CICT & $<0.35 \mu \mathrm{mol} / 1$ & $39 \cdot 7$ & 70 \\
Present study & India & CICT & $<0.70 \mu \mathrm{mol} / 1$ & 90.6 & 100 \\
& & & $<0.35 \mu \mathrm{mol} / 1$ & 100 & 59 \\
\hline \hline
\end{tabular}

might be the less severe vitamin A deficiency in comparison with children in the present study. Prevalence of pre-clinical vitamin A deficiency in the present study was very high (68\% of children had plasma retinol concentrations $<0.35 \mu \mathrm{mol} / 1)$. Data for the prevalence of clinical and pre-clinical vitamin A deficiency in the studies mentioned previously were not reported. Varied criteria for categorizing the CIC/CICT as abnormal in different studies may be another reason for the large variations in sensitivity and specificity of CIC/CICT reported in various studies (Table 3 ).

The CICT technique requires simple materials, is found to be feasible in the field, is less time consuming, and above all shows very good sensitivity and specificity. It can be used in the field especially in less developed countries where prevalence of pre-clinical vitamin A deficiency is likely to be much higher than the prevalence of xerophthalmia. In the present study population $68 \%$ of children had vitamin A deficiency (plasma retinol concentration $<0.35 \mu \mathrm{mol} / 1)$. This is much higher than the presumed pre-clinical vitamin A deficiency of $40 \%$ in category 1 developing countries (Humphrey et al. 1992) including India.

We thank Dr R. K. Chandra, MD, of Janeway Child Health Centre, Newfoundland Drive, St John's, Newfoundland A1A 1R8, Canada, for his advice. We also thank Mrs Rupinder Kaur, Mr Balwant Singh and Mrs Sunita Saproo of this department for assistance in sample collection and Dr Veena Dhawan and Mr Ashwani Munjal for assistance in analysing retinol in plasma.

\section{REFERENCES}

Carlier, C., Moulia-Pelat, J. P., Ceccon, J. F., Mourey, M. S., Fall, M., Diaye, M. N. \& Amedee-Manesme, O. (1991 a). Prevalence of malnutrition and vitamin A deficiency in the Diourbel, Fatick and Kaolack Regions of Senegal: feasibility of the method of impression cytology with transfer. American Journal of Clinical Nutrition $53,66-69$.

Carlier, C., Moulia-Pelat, J. P., Ceccon, J. F., Mourey, M. S., Malvy, D., Fall, M., Diaye, M. N. \& AmedeeManesme, O. (1991 b). Prevalence of malnutrition and vitamin A deficiency in the Diurbel, Fatick, and Kaolack regions of Senegal: a controlled study. American Journal of Clinical Nutrition 53, 74-77.

Gadomski, A. M., Kjolhede, C. L., Wittpenn, J., Rosas, A. R. \& Forman, M. R. (1989). Conjunctival impression cytology (CIC) to detect sub-clinical vitamin A deficiency: comparison of CIC with biochemical assessments. American Journal of Clinical Nutrition 49, 495-500.

Humphrey, J. H., West, K. P. Jr \& Sommer, A. (1992). Vitamin A deficiency and attributable mortality among under-5-year-olds. Bulletin of the World Health Organization 70, $225-232$.

Indian Council of Medical Research (1974). Studies in preschool children. ICMR Technical Report Series 26, 15-19.

Luzeau, R., Carlier, C., Ellrodt, A. \& Amedee-Manesme, O. (1988). Impression cytology with transfer: an easy method for detection of vitamin A deficiency. International Journal for Vitamin and Nutrition Research 58 , 166-170. 
Natadisastra, G., Wittpenn, J. R., Muhilal, West, K. P., Mele, L. \& Sommer, A. (1988). Impression cytology: a practical index of vitamin A status. American Journal of Clinical Nutrition 48, 695-701.

Olson, J. A. (1984). Serum levels of vitamin A and carotenoids as reflectors of nutritional status. Journal of the National Cancer Institute 73, 1439-1444.

Pilch, S. M. (1987). Analysis of vitamin A data from the health and nutrition examination surveys. Journal of Nutrition 117, 636-640.

Reddy, V., Rao, V., Arunjyothi \& Reddy, M. (1989). Conjunctival impression cytology for assessment of vitamin A status. American Journal of Clinical Nutrition 50, 814-817.

Sommer, A. (1989). New imperative for an old vitamin (A). Journal of Nutrition 119, 96-100.

Thurnham, D., Smith, E. \& Flora, P. S. (1988). Concurrent liquid-chromatographic assay of retinol, $\alpha$-tocopherol, $\beta$-carotene, $\alpha$-carotene, lycopene and $\beta$-cryptoxanthin in plasma with tocopherol acetate as internal standard. Clinical Chemistry 34, 377-381.

Wittpenn, J. R., Tseng, S. C. G. \& Sommer, A. (1986). Detection of early xerophthalmia by impression cytology. Archives of Ophthalmology 104, 237-239.

World Health Organization (1982). Control of vitamin A deficiency and xerophthalmia, pp. 7-20. WHO Technical Report Series no. 672. Geneva: World Health Organization. 